\title{
Recent advances in prevention and management of endoscopic retrograde cholangiopancreatography-related duodenal perforation
}

\author{
Guiying Zhu, Fenglin Hu, Changmiao Wang \\ Department of General Surgery, the First Affiliated Hospital of Dalian Medical University, Dalian, Liaoning, China
}

Videosurgery Miniinv 2021; 16 (1): 19-29

DOI: https://doi.org/10.5114/wiitm.2020.101025

\begin{abstract}
Endoscopic retrograde cholangiopancreatography (ERCP) is the main diagnosis and treatment for biliary and pancreatic diseases; however, ERCP requires a high level of technical skill and experience, and there is always a risk of complications. ERCP-related duodenal perforation is one of the most serious complications of ERCP, and although the incidence rate is relatively low, the mortality rate is high. Recently, the introduction of new classification methods and the development of endoscopic technology and equipment have made endoscopic therapy a new trend. This may change the management strategy of perforation. Therefore, we reviewed the latest developments in endoscopic management, surgical management, and conservative internal medicine management. In addition to introducing many new endoscope treatment methods, we also discussed the timing of interventions, the progress of endoscope and surgical indications, and corresponding prevention strategies. We aim to retrospectively analyse these treatment modalities to propose appropriate solutions to improve dynamic clinical therapy.
\end{abstract}

Key words: endoscopic retrograde cholangiopancreatography, duodenal perforation, management, prevention strategy.

\section{Introduction}

Endoscopic retrograde cholangiopancreatography (ERCP) has played a crucial role in the diagnosis and treatment of biliary and pancreatic diseases since it was applied to the clinic in 1968. ERCP-related techniques include endoscopic sphincterotomy (EST), endoscopic papillary balloon dilatation (EPBD), endoscopic nasobiliary drainage (ENBD), endoscopic retrograde pancreatic drainage (ERPD), bile duct or pancreatic duct stent placement, and bile duct or pancreatic duct stone removal. ERCP is more difficult than other endoscopic techniques and has a unique set of complications associated with it that include acute pancreatitis, biliary tract infection, gastrointestinal bleeding, and perforation; some of these are extremely dangerous, such as duodenal perforation [1-3].

latrogenic ERCP-related duodenal perforation is a rare and fatal complication of ERCP, and the incidence ranges from $0.29 \%$ to $3.5 \%$ [4-16], but the highest reported mortality rate is $34.4 \%$ [13]. Due to the low incidence and high mortality, there are few large multi-centre cases. The diagnosis, classification, and treatment methods are numerous, and each is reported to have both advantages and disadvantages [17, 18]. In particular, there are different opinions on treatment methods and timing, which bring about many difficulties in clinical treatment.

Perforations during ERCP are caused by endoscopic sphincterotomy, placement of biliary or duodenal stents, issues with the guidewire, and the

\section{Address for correspondence}

Changmiao Wang, Department of General Surgery, the First Affiliated Hospital of Dalian Medical University, Dalian, Liaoning, China,

e-mail: changmiaowang@yeah.net 
endoscopy itself. According to the mechanism and location of the perforation, the classification of ERCP-related duodenal perforation is constantly updated [19-21]. Treatment mainly includes endoscopic treatment, surgical treatment, and conservative treatment. In the past, ERCP-related duodenal perforation was mainly treated by surgery [4]. However, in recent years, with the development in endoscopic technology and equipment, more and more cases of endoscopic perforation have been treated by endoscopy [7]. Despite this, the indications of surgical and endoscopic treatment remain unclear, and clinicians do not have a unified standard to select and distinguish surgical patients from endoscopic patients. Furthermore, there is no clear explanation for the timing of treatment, which is another issue that determines the efficacy of treatment.

Therefore, we reviewed the surgical and non-surgical management options for therapeutic ERCP-related perforations; we evaluated the main indications for surgical and non-surgical treatment, as well as the timing of treatment. We aimed to propose a scheme that will help to improve dynamic clinical treatment.

\section{Morbidity and mortality}

We retrieved ERCP-related duodenal perforation data from PubMed by reviewing articles reporting more than 10 perforation cases including the terms: "endoscopic retrograde cholangiopancreatography" or "ERCP" combined with "duodenal perforation" in the past 5 years. No other restrictions were imposed. Thirteen of these articles described the incidence of perforations; the incidence rate is $0.8 \%$ (0.29-3.5\%) (Table I). The overall trend has not changed much from the previously reported $0.6 \%$ incidence rate [2], and the more cases studied, the lower the incidence rate. In total, 11 articles described the association of sex with perforation, and demonstrated that perforation is predominantly found in females (70.2\%; range: 50-90\%) although the reason for this remains unknown. Of the retrieved articles, 12 included age descriptions, with an average patient age of 66.2 years (46-75.7 years). In total, 11 articles showed an average case mortality rate of $6.3 \%$ (1.7-34.4\%), an average surgical rate of $20.5 \%$ (3.4-78\%), and an average operative mortality rate of $23 \%(0-50 \%)$.

Table I. List of major studies

\begin{tabular}{|c|c|c|c|c|c|c|c|}
\hline $\begin{array}{l}\text { Time } \\
\text { of article } \\
\text { published }\end{array}$ & $\begin{array}{l}\text { Number of } \\
\text { patients } \\
\text { having ERCP }\end{array}$ & $\begin{array}{c}\text { Number of } \\
\text { patients } \\
\text { with ERCP } \\
\text { perforation (\%) }\end{array}$ & $\begin{array}{c}\text { Number } \\
\text { of female } \\
\text { perforation (\%) }\end{array}$ & $\begin{array}{c}\text { Average age } \\
\text { [years] }\end{array}$ & $\begin{array}{c}\text { Mortality } \\
(\%)\end{array}$ & $\begin{array}{c}\text { Surgery ratio } \\
(\%)\end{array}$ & $\begin{array}{c}\text { Surgery } \\
\text { mortality rate } \\
(\%)\end{array}$ \\
\hline 2020 [4] & 25300 & $380(1.5)$ & & & $16(4.2)$ & $50(13.2)$ & $16(32)$ \\
\hline 2019 [5] & 19468 & $58(0.29)$ & $36(62)$ & 68.5 & $1(1.7)$ & $2(3.4)$ & $1(50)$ \\
\hline 2019 [6] & 342 & $12(3.5)$ & $7(58)$ & 75.7 & & & \\
\hline 2018 [7] & 4196 & $28(0.67)$ & $14(50)$ & 71.3 & $1(3.57)$ & $6(21.4)$ & 1 (16.7) \\
\hline 2018 [8] & 4513 & $36(0.79)$ & $25(69)$ & 72.02 & 4 (11.1) & $28(78)$ & $2(7.1)$ \\
\hline 2018 [9] & 7249 & $35(0.48)$ & $26(74)$ & 59 & $1(2.86)$ & $2(5.7)$ & 0 \\
\hline 2018 [10] & 3492 & $16(0.4)$ & $12(60)$ & 46 & $1(5)$ & $5(25)$ & $1(20)$ \\
\hline 2017 [11] & 6934 & $37(0.53)$ & $25(67)$ & 70 & $4(10.8)$ & $8(22)$ & $1(12.5)$ \\
\hline 2017 [12] & 2423 & $21(0.9)$ & $11(52)$ & 69.7 & $1(4.8)$ & $4(19)$ & $1(25)$ \\
\hline 2016 [13] & 9383 & $29(0.33)$ & $18(62)$ & 70.5 & $10(34.4)$ & $15(51.7)$ & $7(46.6)$ \\
\hline 2016 [14] & 3331 & 79 (2.37) & 71 (90) & 61 & & & \\
\hline 2015 [15] & 4600 & $23(0.5)$ & & 66.7 & $1(4.3)$ & $11(47.8)$ & 0 \\
\hline 2015 [16] & 1923 & $15(0.78)$ & $12(80)$ & 68.5 & $3(20)$ & $8(53)$ & $2(25)$ \\
\hline In total & 93154 & $769(0.8)$ & 257 (70.2) & 66.196 & $43(6.3 \%)$ & 139 (20.5) & $32(23)$ \\
\hline
\end{tabular}




\section{Risk factors}

It was demonstrated that 15 factors increase duodenal perforation in ERCP, including senility, suspected sphincter of Oddi dysfunction (SOD), biliary stricture dilation, papillary stenosis, Billroth II reconstruction, presurgical sphincterotomy, stent-related issues, difficult canulation, unskilled surgeons, hypertension, and long operation time [8, 15] (Table II). Studies showed that SOD was a major risk factor for Stapfer II perforation. Hypertension is a new risk factor [11]. The other factors reported by different medical institution centres are different. Studies from six referral centres in Korea suggested that $37.3 \%$ of perforations were associated with sphincter cuts, about $28.9 \%$ were related to papilla pre-cut, and $25.4 \%$ were related to papilla balloon dilatation [17]. Patil et al. [4] also reported that $30 \%$ of patients with perforations had a history of difficult canulation, $20 \%$ had a pre-cut history, and $8 \%$ had a his- tory of papillary incision. The new study of Niu et al. [3] showed that senility did not increase the risk of perforation.

\section{Classification of ERCP-related duodenal perforation}

According to the mechanism and location of previous perforations, there were four types of ERCP-related duodenal perforations (Table III). Firstly, in 2000, Stapfer et al. [19] classified perforations into four categories (Stapfer I, II, III, and IV). This represents a classic classification that is widely recognised. The location and severity of the perforation were clarified and treatment methods were proposed, but it is difficult to distinguish these four types of perforation in clinical practice. Subsequently, Howard et al. [20], Enns et al. [21], and Kim et al. [22] classified perforations in a variety of ways according to the location of the perforation and the device that

Table II. List of risk factors of iatrogenic duodenal perforations during endoscopic retrograde cholangiopancreatography

\begin{tabular}{|lc|}
\hline Anatomy and disease-related risk factors & Operation-related risk factors \\
\hline Suspicious Oddi sphincter dysfunction & Difficult intubation \\
\hline Billroth II reconstruction & Intramucosal injection of contrast agent, \\
\hline Duodenal diverticulum & Sphincterotomy and nipple pre-incision \\
\hline Papillary stenosis & Biliary stricture dilation \\
\hline Gastrointestinal cancer & Large balloon dilation under endoscopy \\
\hline Senile & Prolonged operation time \\
\hline Female & Inexperience of operating physician \\
\hline
\end{tabular}

Table III. Previous classification of iatrogenic duodenal perforations during endoscopic retrograde cholangiopancreatography

\begin{tabular}{|c|c|c|c|c|}
\hline Type & Stapfer et al. [19] & Howard et al. [20] & Enns et al. [21] & Kim et al. [22] \\
\hline I & $\begin{array}{l}\text { Lateral or medial duodenal } \\
\text { wall perforation, endo- } \\
\text { scope related }\end{array}$ & Guidewire perforation & $\begin{array}{c}\text { Oesophageal, gastric, and } \\
\text { duodenal perforation }\end{array}$ & Scope itself \\
\hline$\|$ & $\begin{array}{l}\text { Periampullary perforations, } \\
\text { sphincterotomy related }\end{array}$ & Periampullary perforation & Periampullary perforation & $\begin{array}{l}\text { Needle knife used during } \\
\text { the sphincterotomy }\end{array}$ \\
\hline III & $\begin{array}{l}\text { Ductal or duodenal perfo- } \\
\text { rations due to endoscopic } \\
\text { instruments }\end{array}$ & Duodenal perforation & $\begin{array}{l}\text { Guidewire-related perfo- } \\
\text { ration }\end{array}$ & $\begin{array}{c}\text { Guidewire and is associ- } \\
\text { ated with the least risk of } \\
\text { contamination }\end{array}$ \\
\hline IV & $\begin{array}{l}\text { Guidewire-related perfo- } \\
\text { ration with presence of } \\
\text { retroperitoneal air at X-ray }\end{array}$ & None & None & None \\
\hline
\end{tabular}


Table IV. New classification of iatrogenic duodenal perforations during endoscopic retrograde cholangiopancreatography

\begin{tabular}{|lccc|}
\hline Type & Mitek et al. [18] & Bray et al. [12] & Wu et al. [23] \\
\hline I & $\begin{array}{c}\text { Extraperitoneal (Duodenum except } \\
\text { for duodenal bulb) Common bile } \\
\text { duct Ampulla of Vater }\end{array}$ & $\begin{array}{c}\text { Retroperitoneal contrast identified } \\
\text { during ERCP }\end{array}$ & Air-alone groups \\
\hline II & Intraperitoneal Duodenal bulb & $\begin{array}{c}\text { Retroperitoneal air on subsequent } \\
\text { imaging }\end{array}$ & Air-fluid groups \\
\hline III & None & $\begin{array}{c}\text { Retroperitoneal fluid on subsequent } \\
\text { imaging }\end{array}$ & Fluid-alone groups \\
\hline IV & None & Intraperitoneal air or fluid & None \\
\hline
\end{tabular}

caused the perforation, but all have problems similar to the Stapfer classification. Because the perforation detection rate of ERCP intraoperative diagnosis is only $23.3 \%$, and because of bleeding and infection after ERCP, it is more difficult to distinguish the location and type of perforation, which limits the clinical usefulness of these classifications; thus, a better classification is required [16]. In recent years, three new classifications have emerged (Table IV). Miłek et al. [18] preferred a classification treatment based on intraperitoneal and extraperitoneal perforation, while Bray et al. [12] and Wu et al. [23] proposed a classification based on computed tomography (CT) scan. The Wu et al. [23] classification divides patients into air-alone, air-fluid, and fluid-alone groups. This method is a good supplement, especially when the Stapfer classification cannot be used after ERCP, and it can also distinguish the severity of perforation. It may become an important classification method to

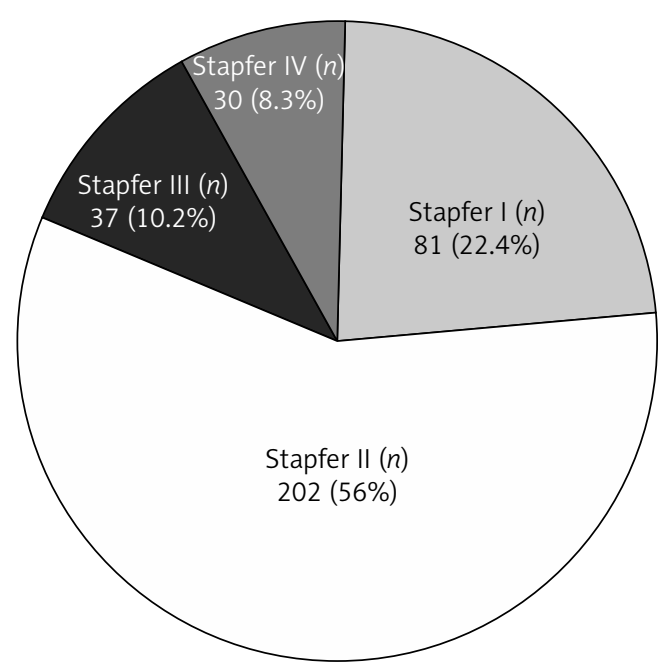

Figure 1. The proportion of Stapfer classification distinguish non-surgical patients in the future. At present, the typing method proposed by Stapfer is used at home and abroad, and Stapfer II is the most common in the clinic (Figure 1). The high incidence of Stapfer II is related to more clinical canulation difficulties and papilla pre-cutting operations.

\section{Diagnosis of ERCP-related duodenal perforation}

Mortality can be reduced by early diagnosis and early appropriate interventions. The diagnosis rate varies greatly in different literature. Intraoperative diagnosis of ERCP-related duodenal perforation can identify the type of perforation and process it immediately; however, the diagnosis rate (8.4-100\%) needs to be improved $[4,5,16,17,24]$. The conscious training of doctors before ERCP, the comparison of patients undergoing preoperative $X$-ray examination, and $X$-ray or fluorescence examination during and after ERCP can greatly improve the diagnosis rate of perforation [25]. The amount of retroperitoneal air may be independent of the size of the perforation, but rather the endoscope blows in the air during ERCP. The degree is related, and it is best to mirror carbon dioxide, which is capable of rapid absorption and high contrast [14].

\section{Treatment}

In recent years, endoscopic treatment ERCP-related perforations have gradually replaced surgery. Especially with the rapid development of endoscopic treatment methods and equipment, Endoclips, Endoloops, the over-the-scope clip system (OTSC), fully covered self-expandable metallic stents (FC-SEMS), and fibrin sealants have been successfully applied. 
These advances not only make endoscopic treatment safe and feasible, but also shorten the length of hospital stay, reduce the cost, and reduce the trauma and complications caused by surgery [2630]. However, in certain cases surgery still needs to be considered. Conservative therapy is the basis of treatment and needs to be used in most patients.

\section{Timing of treatment}

The treatment and prognosis of ERCP-related duodenal perforation are closely related to time (Figure 2), which is also an important factor in determining the most appropriate treatment. A particular emphasis is placed on early diagnosis and early differentiation between surgical and non-surgical cases, and delayed surgery can greatly increase mortality. However, the definition of 'early' is unclear. It is reported that the intervention time is mainly during ERCP and 12 h, 24 h, 72 h after ERCP [5, 7, 13, 24]. First, delays greater than $72 \mathrm{~h}$ were generally not controversial because the prognosis was poor [13, 16]. Secondly, several studies have demonstrated that an abdominal scan before ERCP, especially a computed tomography $(\mathrm{CT})$ scan, will greatly improve the intraoperative diagnosis rate of ERCP-related duodenal perforation. If the perforation is found during surgery and directly treated by endoscopic methods, the postoperative complications and mortality will be reduced. Indeed, this is the best time to treat; even if the endoscopic treatment fails, early surgery can be performed and the prognosis is better [5, 7 , 14]. Finally, some studies have shown that the mortality rate within $12 \mathrm{~h}$ of diagnosis and treatment was within $10 \%$, and the difference between surgery and endoscopic treatment was small $[10,11,15,17$, 24]. The mortality rate increased after $24 \mathrm{~h}$, and the surgical mortality rate could be as high as $50 \%[4,5$, $13,16,18]$. At the same time, it is worth noting that there are studies that suggest a 12-hour diagnosis, with a total mortality rate of $4.3 \%$ and zero surgical mortality [15]. Therefore, early diagnosis and treatment recommendations are considered to be most effective within $12 \mathrm{~h}$ and no later than $24 \mathrm{~h}$.

\section{Endoscopic indications}

With the development of endoscopic techniques, reports of endoscopic treatment perforations have increased in recent years. Most reports suggest that perforation should be directly treated by ERCP if the perforation is found during ERCP. For example, Shi et al. [5] reported the successful treatment of Stapfer I, Stapfer II, as well as perforation of the duodenum horizontal, large perforation with endoscopy $[5,8]$. All were previously recommended for surgery. This suggested that the size and type of perforation was no longer the main factor in distinguishing surgical and non-surgical patients. Simultaneous endoscopic treatment is also feasible after perforation of ERCP. Indeed, surgical and endoscopic comparison results by Artifon et al. [15] also showed that within $12 \mathrm{~h}$ of ERCP, the success rate of endoscopic and surgical treatment was $100 \%$ regardless of the size and type of perforation. Jin et al. [17] considered that there was no systemic inflammatory response (SIS) or peritonitis (PIS) in perforation, and thus no preferred endoscopic treatment. Kumbhari et al. [14] proved that SIS was no longer a surgical indication. Therefore, time may be important to distinguish endoscopic patients. The perforations found during ERCP can be treated directly under the endoscope. For postoperative perforation, endoscopic closure can be attempted within $24 \mathrm{~h}$, and especially within $12 \mathrm{~h}$, but PIS needs to be ruled out.

\section{Endoscopic modes}

It was demonstrated that 14 endoscopic methods treat perforations (Table V, Figure 3 ). There is no unified standard for the selection of methods. We have described them briefly based on the initial closure and reclosure. Jimenez Cubedo et al. [8] reported the first closure of a human duodenal perforation using an endoscope. First, for the initial closure of

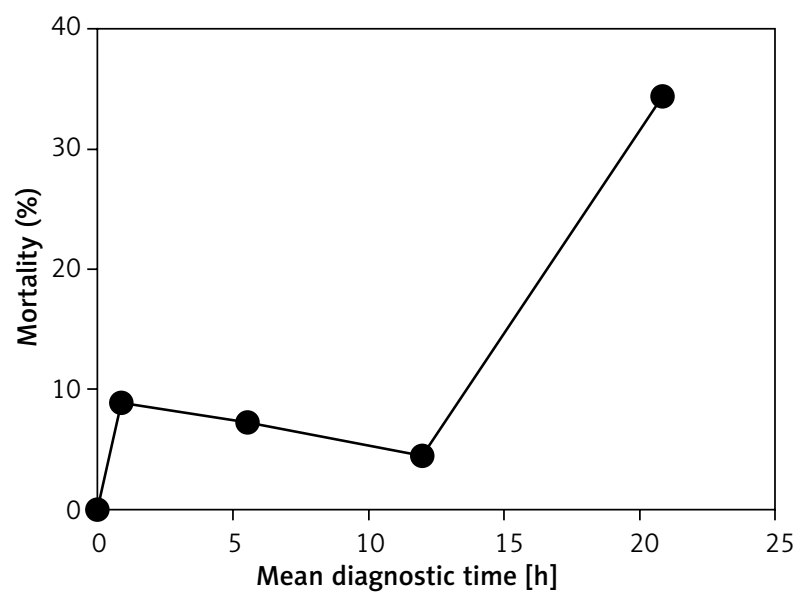

Figure 2. Diagnosis or treatment time and mortality reported in some literature 
Table V. Characteristics of perforation and corresponding endoscopic treatment methods

\begin{tabular}{|c|c|c|c|c|c|c|c|c|c|}
\hline $\begin{array}{l}\text { Endoscopic } \\
\text { modes }\end{array}$ & $\begin{array}{l}\text { Endoclips } \\
\text { or } \\
\text { Endoloops } \\
\text { or OTSC. }\end{array}$ & FC-SEMS & Fibrin glue & $\begin{array}{l}\text { Purse-string } \\
\text { suture }\end{array}$ & EBL & $\begin{array}{l}\text { Covered } \\
\text { metal stent }\end{array}$ & $\begin{array}{c}\text { ENPT or } \\
\text { vacuum } \\
\text { therapy } \\
\text { with OFD }\end{array}$ & $\begin{array}{c}\text { Endoscopic } \\
\text { scissor and } \\
\text { Clips }\end{array}$ & $\begin{array}{c}\text { Tulip } \\
\text { bundle }\end{array}$ \\
\hline $\begin{array}{l}\text { Perforation } \\
\text { type }\end{array}$ & $\begin{array}{l}\text { Stapfer I } \\
(1-2 \mathrm{~cm})\end{array}$ & $\begin{array}{c}\text { Stapfer II } \\
\text { and III }\end{array}$ & $\begin{array}{l}\text { Stapfer II } \\
\text { and Sec- } \\
\text { ondary } \\
\text { closure }\end{array}$ & $\begin{array}{l}\text { Stapfer I } \\
(2 \mathrm{~cm}) \\
\text { and Tita- } \\
\text { nium clips } \\
\text { failed }\end{array}$ & $\begin{array}{l}\text { Any per- } \\
\text { foration } \\
(1-2 \mathrm{~cm} \\
\quad \text { and } \\
>2 \mathrm{~cm})\end{array}$ & $\begin{array}{l}\text { Balloon } \\
\text { dilation }\end{array}$ & Stapfer II & $\begin{array}{c}\text { Stent } \\
\text { displace- } \\
\text { ment }\end{array}$ & $\begin{array}{l}\text { OTSC } \\
\text { failed }\end{array}$ \\
\hline
\end{tabular}

$E B L$ - double endoscopic band ligation, ENPT - endoscopic negative pressure therapy, OFD - open-pore film drainage.

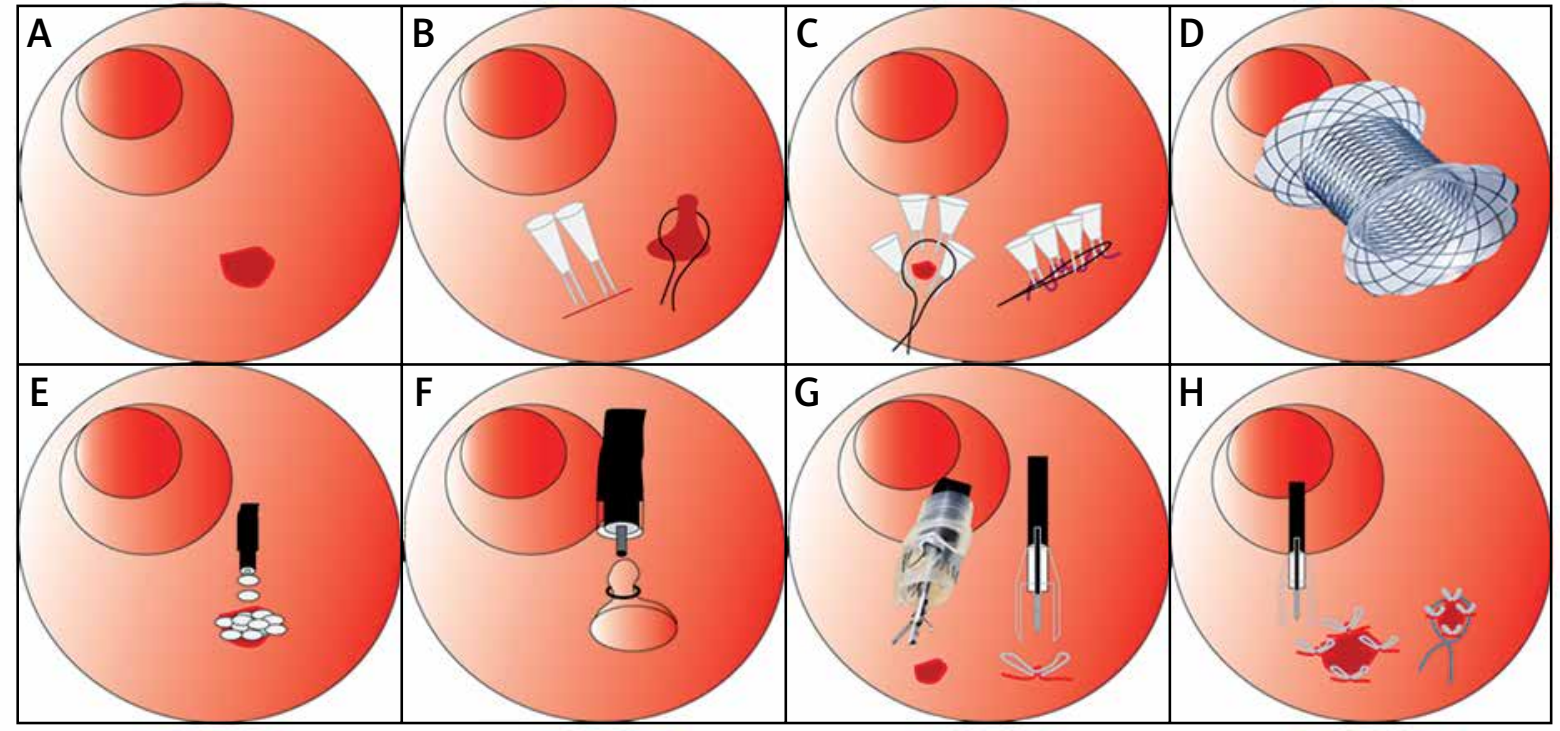

Figure 3. Therapeutic diagram of endoscopic closing duodenal perforations. A - Endoscopic retrograde cholangiopancreatography (ERCP)-related duodenal perforations. B - Endoclips and Endoloops. C - Pursestring suture. D - Fully covered self-expandable metallic stent (FC-SEMS). E - Fibrin glue. F - Endoscopic band ligation (EBL). G - Over-the-scope clip (OTSC). H - Tulip bundle

the perforation, especially the perforation found in the endoscope, an initial closure can be performed using an endoscopic clip and an endoscopic ring, an endoscopic clip and an annulus, OTSC, and an under cap-assisted endoscopy [5, 24, 25, 28]. For small perforations $(<1 \mathrm{~cm})$, a single endoscope clip is sufficient. For larger perforations $(>1 \mathrm{~cm})$, it is best to combine Endoloops and Endoclips, double endoscopic band ligation and Endoclipping, and multiple endoscopic devices [31, 32]. In double lumen endoscopically, a plurality of titanium clips should be used to secure the snare to the perforated edge before tightening the snare. The device is then closed to the perforation $(3 \mathrm{~cm})$. When the perforation of the duodenal bulb is initially closed, it is better to perform endoscopic titanium clip closure. For perforations that occur at the junction of the duodenal bulb and descending part, due to the acute angle of the anatomical structure, the use of a front-view ERCPscopy with a transparent cap during using titanium clamps to close this perforation can provide a good field of view and can effectively clamp the perforation [28]. If a duodenoscope is used, the difficulty of surgery will increase.

Drainage is important for prognosis when treating perforation. Immediate placement of metallic Endoclips, covered metal stent, self-expandable metallic stents (SEMS), and fully covered self-expandable metal stents (FC-SEMS) can close perforations more effectively $[29,30]$. This can reduce peritonitis and shorten hospital stays by reducing patient pain and white blood cell counts. In particular, FC-SEMS has been widely reported in recent years for the treatment of Stapfer II perforations. Reports showed 
that FC-SEMS played a role not only in biliary drainage but also in sealing perforations. Since the FCSEMS may block the perforated area by radial force, the perforated area can heal quickly [5].

Endoscopic fibrin sealant and tulip bundle rescue can be used to close a failed perforation for the first time [22, 27, 31]. Fibrin is an adhesive that contains fibrinogen and thrombin, which can promote tissue repair for up to 2 weeks and can be absorbed by both macrophages and fibroblasts. In cases of endoscopy failure due to insufficient titanium clamp closure, it is also conceivable to use fibrin adhesive alone. For perforation located in the retroperitoneum, retroperitoneal tissue prevents fibrin adhesives from working, and the diffusion effectively seals the perforations. The tulip bundle was used for closure after failure was reported for the first time. Zimmer et al. [33] reported that "tulip bundled rescue" could be used for Stapfer I perforation that OTSC failed to treat.

Endoscopic nasobiliary drainage (ENBD) and endoscopic retrograde biliary drainage (ERBD) can be used alongside adjuvant treatment at the same time. Loske et al. [30] reported endoscopic vacuum therapy with a novel open-pore film drainage (OFD) treatment for perforation. These methods can be used for both small and large perforation-assisted treatment.

\section{Surgical indications}

In the past, ERCP complicated duodenal perforation advocated surgical treatment. However, with the results of endoscopic treatment, many indications have changed. Changes in surgical indications are mainly based on classification, clinical symptoms and signs, and the severity of the disease. Firstly, Stapfer I, Howard III, and Enns III perforations are classified as large perforations, and surgery was recommended performed immediately in the past [14, 19-21]. But now Shi et al. [5] disagree because they successfully treated Stapfer I perforations with endoscopy. Secondly, the surgery is sometimes determined based on imaging data. Indeed, Rabie et al. [34] believe that liquid on the CT is an indication for surgery. They proposed three surgical hard signs: contrast agent extravasation, ascites, and intra-abdominal air, as well as a series of soft signs: duodenal wall thickening, air in the duodenal wall, and retroperitoneal air. If the diagnosis is conservative within $24 \mathrm{~h}$, without improvement or worsening, the abdomen should be opened [18]; another angle is the general vital signs and symptoms. Koc et al. [35] suggest that surgery should be performed if the systolic blood pressure is lower than $90 \mathrm{~mm} \mathrm{Hg}$, heart rate is higher than 120 beats/min, and the body temperature is greater than $38^{\circ} \mathrm{C}$. Moreover, obvious symptoms of abdominal pain are planned indications for surgery. Jin et al. [17] suggested that the mortality of ERCP-related duodenal perforation is associated with peritoneal irritation (PIS) and the systemic inflammatory response (SIS), and they advised that surgery should be performed promptly following the appearance of these two symptoms. In summary, almost all researchers believed that sepsis is an indication for immediate surgical intervention; these are common signs, but some are not particularly common. A study of surgery and endoscopic treatment by Patil et al. [4] found that high total leukocyte count (TLC) and hypoalbuminaemia occurred $12 \mathrm{~h}$ after ERCP, and non-surgical treatment was prone to failure, which was an indication for planned surgery. Furthermore, Kumbhari et al. [14] reported the relationship between perforation size and surgery and found that most patients with a perforation diameter greater than $1 \mathrm{~cm}$ underwent surgical treatment. Also, many recent studies have proposed that patients should be comprehensively managed, rather than focusing on a certain clinical manifestation. Theopistos et al. [7] stated that a plan should be formulated based on the patient's diagnosis time, clinical symptoms, and disease progression [15]. The clear clinical symptoms are abdominal tenderness, rebound tenderness, and muscle tension. Moreover, imaging findings have suggested that CT or ERCP massive contrast agent exudation, CT-enhanced scan that confirms large intra-abdominal or retroperitoneal effusion, huge subcutaneous emphysema, unrelieved biliary obstruction, and foreign bodies in the bile duct that fail to be expelled are representative of cases that require immediate surgery. In addition, a number of researchers have identified non-surgical indications. Tavusbay et al. [13], Stapfer et al. [19], and Kim et al. [22] have indicated that simple retroperitoneal air should not be used as an indication for surgery [8, 19]; therefore, the consideration of Theopistos et al. [7] may be better for the clinic. If PIS occurs, radiologically persistent leaks and vital signs are unstable, surgical intervention may be better within $24 \mathrm{~h}$ of ERCP but is not recommended after $72 \mathrm{~h}$. 


\section{Surgical methods}

The surgical interventions commonly used to treat ERCP-related perforations include duodenal suture, retinal patch repair, pyloric exclusion, gastrointestinal anastomosis, and T-tube drainage with or without cholecystectomy [17, 19, 20]. Koc et al. [35] also reported extensive surgical procedures for the treatment of ERCP-related perforations, including the following: simple retroperitoneal drainage; insertion of a perforated T-tube for duodenal repair; common bile duct exploration and T-tube placement; duodenal resection and gastric jejunum anastomosis or gastrojejunostomy; pyloric exclusion and pancreaticoduodenectomy; laparoscopic cholecystectomy (LC) + common bile duct exploration (LCBDE) + T-tube + intra-abdominal and/or retroperitoneal drainage; biliary exploration; and biliary derivation $[8,35]$. Surgery is associated with many factors, including underlying disease, and the size and location of the perforation. In patients with perforation due to problems such as papilla incision or biliary stenosis, bile duct exploration, duodenal repair, T-tube drainage, and jejunostomy are required. In cases where the perforation of the intestinal wall is large, due to technical inexperience and side view angle problems, further perforation repair is needed. For the perforation of the intestinal wall far away from the duodenal papilla, usually due to a large perforation and a short endoscope, simple duodenal suture is not ideal, and gastrointestinal anastomosis and ostomy are required. The most common surgical method is a simple duodenal suture with or without omental fixation (93.7\%) [2].

\section{Conservative treatment}

The consensus is that ERCP patients need intestinal rest, parenteral nutrition, intravenous and/or oral antibiotics during perforation treatment, and the symptomatic use of proton pump inhibitors and somatostatin to maintain the stability of the internal environment $[5,13,15,24]$. If the perforation is small, or if it is only retroperitoneal air, the patient can be treated with medication alone. If retroperitoneal or peritoneal effusion is present, percutaneous drainage is performed under CT guidance [23]. In specific drug treatment, research by Bray et al. [12] showed that early antibiotic use is beneficial for prognosis.

\section{Prevention strategy}

Because some patients are prone to ERCP-related perforations, the risk factors of ERCP-related perforation should be considered, and measures should be taken to prevent the occurrence of perforation as much as possible.

\section{Prevention of patient-related risk factors}

First, for patients with gastrointestinal reconstruction involving the duodenum, and patients with biliary and pancreatic tumours, the application of duodenoscopy to ERCP can easily cause bowel perforation; the choice of a front-view ERCPscopy can reduce this risk of perforation. Secondly, there is a risk of perforation when there is a diverticulum or diverticulum papilla adjacent to the duodenal papilla [36]; to avoid this, a small incision + balloon dilation or a simple balloon dilation can be performed.

\section{Prevention of operation-related risk factors}

First, duodenal papillary incision is performed in cases with difficult canulation. Although the risk of perforation is high, the use of new instruments, such as the DUAL knife, can reduce this risk. Second, the use of larger diameter balloons to dilate the duodenal papilla, or the presence of bile duct stenosis, carries a high risk of perforation, so the use of excessively large diameter balloons for dilation should be avoided. Third, the risk of perforating the duodenal papillectomy is high, and the indications for this operation should be carefully considered. If a longer stent needs to be placed, using another type of stent (dual pigtail type) may prevent perforation [11]. Moreover, it is necessary to perform the surgery carefully and to try to operate under X-ray surveillance. During the operation, close attention should be paid to the X-ray fluoroscopy image, and signs of perforation should be found early to facilitate early treatment [25].

\section{Discussion}

Our review of ERCP-related duodenal perforation suggests that perforation related to ERCP is inevitable, and identified risk factors that can improve prognosis [2]. Mortality can be reduced by early diagnosis and early appropriate interventions. The classification of perforation is mainly based on the mechanism, location, and treatment. There are sev- 
en main classifications, of which the first four have been mentioned in previous literature [19, 22]. The latter three categories are classified according to videography location and severity and were not covered in previous literature. Compared to other classifications, Stapfer classification is detailed and reasonable, but it was difficult to use in clinical practice. The Wu et al. [23] method is a good supplement, especially when the Stapfer classification cannot be used after ERCP, and it can also distinguish the severity of perforation. It may become an important classification method to distinguish non-surgical patients in the future.

In the past, the treatment of ERCP-related perforation was mainly surgical. However, in recent years, with the development of endoscopic treatment technology, many cases that were previously considered to require surgical treatment have been successfully treated by non-surgical means. Our systematic review also suggests that a non-surgical approach is feasible [28]. Endoscopic treatment has advantages in mortality, hospital stay, and complications. In particular, the combined application of multiple endoscopic devices, such as Endoclips, Endoloops, and OTSC, has led to the successful treatment of many large perforations, which can be successfully treated by endoscopic stent implantation, even if accompanied by massive exudation [29, 36, 37]. The majority studies also have suggested that obvious and continuous abdominal pain, as well as continuous fluid or contrast agent leakage under CT or ERCP, are operative hard indications. Early leakage can be treated with endoscopy, but surgical treatment is recommended because surgery that is delayed more than $24 \mathrm{~h}$ greatly increases mortality [16]. Retroperitoneal air is no longer an indication for surgery. Surgical and endoscopic interventions are closely related to the timing of treatment. Endoscopic treatment can be successfully performed early (less than $24 \mathrm{~h}$ ), excluding cases with hard indications, especially for perforations within $12 \mathrm{~h}$. Furthermore, surgical treatment can be continued even if endoscopic treatment is unsuccessful. Therefore, we proposed a simple algorithm such as that outlined in Figure 4, to provide some suggestions for clinical, especially endoscopic treatment.

Recent advances in ERCP endoscopic treatment related to duodenal perforation are exciting, primarily in the early $(<12 \mathrm{~h})$ and early diagnosis of patients with advanced equipment and expert use of endoscopes, endoscopic clips, endoscopic suturing device, fibrin sealant, and SEMS insertion. This has benefited many patients. However, based on the complexity of the clinical status of the perforation, there is currently no clear consensus on the best treatment regimen that can be used in all cases.

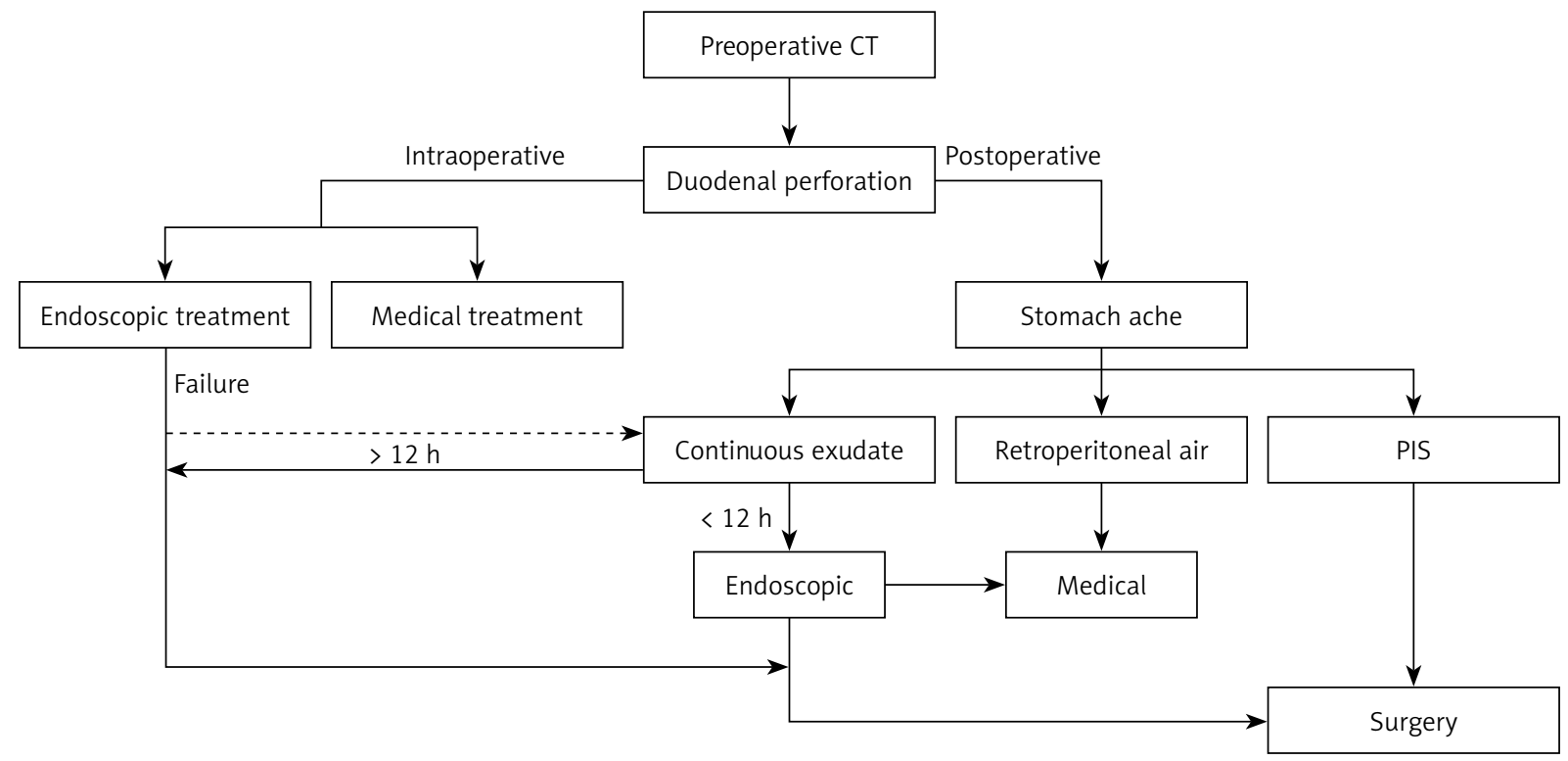

Figure 4. Algorithm of the management of endoscopic retrograde cholangiopancreatography (ERCP)-related duodenal perforations

PIS - peritonitis. 
In the future, more comparisons between prospective trials between endoscopy and surgery and new methods of endoscopy may be needed. The current view has a number of limitations. Although the quality of the included papers is good and the numbers of cases are relatively large, they also include many new endoscopic treatments. Furthermore, there are fewer cases, especially the comparison between endoscopy and surgery, and there is only one randomisation.

\section{Conclusions}

Although duodenal perforation after ERCP is uncommon, if it is not treated adequately and promptly, it can cause serious complications. In particular, in elderly women at high risk, preoperative evaluation by abdominal scan is necessary. Preoperative scanning and careful observation during ERCP can greatly improve the intraoperative diagnosis rate. Once perforation is found in ERCP, endoscopic treatment can be performed regardless of the size of the aperture, as can a combination, and repeated application, of multiple endoscopic techniques. There is also the question of surgical intervention. Surgical treatment has decreased in recent years. However, since delayed surgery can greatly increase mortality, experienced surgeons should be consulted at the same time as conservative treatments are administered. Surgery remains necessary once a perforation continues to exfoliate, or in cases with severe peritonitis and sepsis. Above all, non-surgical treatment is feasible if the perforation is noted early and management of the perforation and peritoneal contamination is minor. Even in cases with fluid leakage, it is possible to treat by drainage and decompression; however, once there is a continuous large amount of exudate and severe peritonitis, or even sepsis, surgery is still preferred.

\section{Acknowledgments}

The authors would like to thank all the individuals that provided technical assistance and valuable advice.

This study was supported by the National Natural Science Foundation of China (No. 81774082).

\section{Conflict of interest}

The authors declare no conflict of interest.

\section{References}

1. Manoharan D, Srivastava DN, Gupta AK, et al. Complications of endoscopic retrograde cholangiopancreatography: an imaging review. Abdom Radiol (NY) 2019; 44: 2205-16.

2. Cirocchi R, Kelly MD, Griffiths EA, et al. A systematic review of the management and outcome of ERCP related duodenal perforations using a standardized classification system. Surgeon 2017; 15: 379-87.

3. Niu F, Liu YD, Chen RX, et al. Safety and efficacy of enhanced recovery after surgery in elderly patients after therapeutic endoscopic retrograde cholangiopancreatography. Videosurgery Miniinv 2019; 14: 394-400.

4. Patil NS, Solanki N, Mishra PK, et al. ERCP-related perforation: an analysis of operative outcomes in a large series over 12 years. Surg Endosc 2020; 34: 77-87.

5. Shi D, Yang JF, Liu YP. Endoscopic treatment of endoscopic retrograde cholangiopancreatography-related duodenal perforations. J Laparoendosc Adv Surg Tech A 2019; 29: 385-91.

6. González Valverde FM, Fernández López AJ. Management of duodenal perforations after endoscopic retrograde cholangiopancreatography. Rev Esp Enferm Dig 2019; 111: 331-3.

7. Theopistos V, Theocharis G, Konstantakis C, et al. Non-operative management of type 2 ERCP-related retroperitoneal duodenal perforations: a 9-year experience from a single center. Gastroenterology Res 2018; 11: 207-12.

8. Jiménez Cubedo E, López Monclús J, Lucena de la Poza JL, et al. Review of duodenal perforations after endoscopic retrograde cholangiopancreatography in Hospital Puerta de Hierro from 1999 to 2014. Rev Esp Enferm Dig 2018; 110: 515-9.

9. McCarthy CJ, Butros SR, Dawson SL, et al. Image-guided percutaneous management of duodenal perforation following endoscopic retrograde cholangiopancreatography (ERCP): assessment of efficacy and safety. Clin Radiol 2018; 73: 319.e9-e15.

10. Bostancı Ö, Battal M, Yazıcı P, et al. Management of iatrogenic injuries due to endoscopic sphincterotomy: surgical or conservative approaches. Turk J Surg 2018; 34: 24-7.

11. Weiser R, Pencovich N, Mlynarsky L, et al. Management of endoscopic retrograde cholangiopancreatography-related perforations: experience of a tertiary center. Surgery 2017; 161: 920-9.

12. Bray MS, Borgert AJ, Folkers ME, et al. Outcome and management of endoscopic retrograde cholangiopancreatography perforations: a community perspective. Am J Surg 2017; 214: 69-73.

13. Tavusbay C, Alper E, Gökova M, et al. Management of perforation after endoscopic retrograde cholangiopancreatography. Ulus Travma Acil Cerrahi Derg 2016; 22: 441-8.

14. Kumbhari V, Sinha A, Reddy A, et al. Algorithm for the management of ERCP-related perforations. Gastrointest Endosc 2016; 83: $934-43$.

15. Artifon EL, Minata MK, Cunha MA, et al. Surgical or endoscopic management for post-ERCP large transmural duodenal perforations: a randomized prospective trial. Rev Gastroenterol Peru 2015; 35: 313-7.

16. Armas Ojeda MD, Ojeda Marrero V, Roque Castellano C, et al. Duodenal perforations after endoscopic retrograde cholangiopancreatography. Cir Esp 2015; 93: 403-10. 
17. Jin YJ, Jeong S, Kim JH, et al. Clinical course and proposed treatment strategy for ERCP-related duodenal perforation: a multicenter analysis. Endoscopy 2013; 45: 806-12.

18. Miłek T, Ciostek P, Porzycki P, et al. Treatment results of gastrointestinal perforation after endoscopic retrograde cholangiopancreatography. Gastroenterology Rev 2013; 8: 299-304.

19. Stapfer M, Selby RR, Stain SC, et al. Management of duodenal perforation after endoscopic retrograde cholangiopancreatography and sphincterotomy. Ann Surg 2000; 232: 191-8.

20. Howard TJ, Tan T, Lehman GA, et al. Classification and management of perforations complicating endoscopic sphincterotomy. Surgery 1999; 126: 658-65.

21. Enns R, Eloubeidi MA, Mergener K, et al. ERCP-related perforations: risk factors and management. Endoscopy 2002; 34: 293-8.

22. Kim BS, Kim IG, Ryu BY, et al. Management of endoscopic retrograde cholangiopancreatography-related perforations. J Korean Surg Soc 2011; 81: 195-204.

23. Wu JH, Tsai HM, Chen CY, et al. Computed tomography classification of endoscopic retrograde cholangiopancreatography-related perforation. Kaohsiung J Med Sci 2020; 36: 129-34.

24. Li G, Chen Y, Zhou X, et al. Early management experience of perforation after ERCP. Gastroenterol Res Pract 2012; 2012: 657418.

25. Motomura Y, Akahoshi K, Gibo J, et al. Immediate detection of endoscopic retrograde cholangiopancreatography-related periampullary perforation: fluoroscopy or endoscopy? World J Gastroenterol 2014; 20: 15797-804.

26. Weiland T, Fehlker M, Gottwald T, et al. Performance of the OTSC System in the endoscopic closure of iatrogenic gastrointestinal perforations: a systematic review. Surg Endosc 2013; 27: 2258-74.

27. Yang HY, Chen JH. Endoscopic fibrin sealant closure of duodenal perforation after endoscopic retrograde cholangiopancreatography. World J Gastroenterol 2015; 21: 12976-80.

28. Lee TH, Bang BW, Jeong JI, et al. Primary endoscopic approximation suture under cap-assisted endoscopy of an ERCP-induced duodenal perforation. World J Gastroenterol 2010; 16: 2305-10.

29. Erkan P, Seref KA, Tarık EA, et al. Fully covered self-expandable metal stens eliminate surgical repair requirements in both endoscopic sphincterotomy and precut sphincterotomy-related perforation (with video). Eur J Gastroenterol Hepatol 2020; 32: 557-62.

30. Loske G, Rucktäschel F, Schorsch T, et al. Successful endoscopic vacuum therapy with new open-pore film drainage in a case of iatrogenic duodenal perforation during ERCP. Endoscopy 2015; 47: E577-8.

31. Li Q, Ji J, Wang F, et al. ERCP-induced duodenal perforation successfully treated with endoscopic purse-string suture: a case report. Oncotarget 2015; 6: 17847-50.

32. Kim K, Kim EB, Choi YH, et al. Repair of an endoscopic retrograde cholangiopancreatography-related large duodenal perforation using double endoscopic band ligation and endoclipping. Clin Endosc 2017; 50: 202-5.

33. Zimmer V, Exner $\mathrm{S}$. "Tulip bundle rescue" troubleshooting overthe-scope clip (OTSC) failure in ERCP-related duodenal perforation (Stapfer I). Dig Liver Dis 2018; 50: 514.
34. Rabie ME, Mir NH, Al Skaini MS, et al. Operative and non-operative management of endoscopic retrograde cholangiopancreatography-associated duodenal injuries. Ann R Coll Surg Engl 2013; 95: 285-90.

35. Koc B, Bircan HY, Adas G, et al. Complications following endoscopic retrograde cholangiopancreatography: minimal invasive surgical recommendations. PLoS One 2014; 9: e113073.

36. Park TY, Bang CS, Choi SH, et al. Forward-viewing endoscope for ERCP in patients with Billroth II gastrectomy: a systematic review and meta-analysis. Surg Endosc 2018; 32: 4598-613.

37. Liu Y, Wang D, Li Z. Endoscopic cosure for EUS and ERCP related duodenal perforation by endoclips. Gastroenterol Res Pract 2016; 2016: 1051597.

Received: 27.08.2020, accepted: 23.09.2020. 